FedUni ResearchOnline http://researchonline.federation.edu.au

This is the author's accepted version of the following publication:

Devlin, M. (2013) Effective University leadership and management of learning and teaching in a wide participation context: Findings from two national Australian studies. Tertiary Education and Management, 19(3) pp. 233-245.

The version displayed here may differ from the final published version. The final publication is available at:

http://dx.doi.org/10.1080/13583883.2013.793380

Copyright 2013 European Higher Education Society 
Effective university leadership and management of learning and teaching in a widening participation context:

Findings from two national Australian studies

Marcia Devlin

The University of Ballarat

P.O. Box 668

Ballarat

Victoria

Australia 3353

mttdevlin@gmail.com 
Effective university leadership and management of learning and teaching in a widening participation context: Findings from two national Australian studies

\author{
Marcia Devlin \\ The University of Ballarat
}

The widening participation agenda in Australian higher education heralds changes that demand fresh thinking in university leadership and management of learning and teaching. The findings from interviews across two national studies in 16 Australian universities with 50 staff and 89 successful students from low socioeconomic backgrounds, provide the basis for new directions related to the leadership and management of university teaching and learning in the context of an increasingly diverse student body. These directions relate to: institutional strategic alignment; reward for and recognition of teachers; appropriate resourcing; and effective structure and organisation of teaching and learning support.

\title{
Introduction
}

The federal government response to the 2008 Bradley Review of higher education in Australia (Bradley, Noonan, Nugent, \& Scales, 2008) includes a targeted increase in the number and proportion of students from low socioeconomic status (LSES) participating in higher education within the next decade. However, several commentators have noted the need to focus not only on recruitment and participation but also on the retention and success of LSES students. As Tinto (2008) has argued, access without support does not constitute real opportunity for these students and as Devlin (2010b) notes, it would be "a moral and economic tragedy" (np) to attract LSES students to university without having made the changes necessary to retain them and facilitate their success. These changes include those related to effective teaching and support, but particularly to the leadership and management of learning and teaching and associated support that underpins these changes.

As the federal government identified in Transforming Australia's Higher Education System (Australian Government, 2009), its response to the Bradley Review:

Maintaining and improving the quality of teaching, learning and the student experience is a critical factor in the success of universities ... there will also need to be an increased emphasis on improving the student learning experience in order to boost retention, progress and ultimately, completion rates (p. 15).

In order to meet the national targets related to increased numbers of LSES students in higher education, institutional leadership and management that is specifically focused on increasing the retention of, and ensuring a high quality experience for, LSES students is necessary. This paper examines, from a research- and evidencebased perspective, how Australian universities might best lead and manage to effectively support, include, retain, and graduate LSES student cohorts who are now beginning to enter Australian programs with greater diversity in preparedness and 
social capital than ever before.

Work on higher education leadership by Fullan and Scott (2009) and Scott et al. (2008) highlights the enormous complexity of the role of university leaders in teaching and learning and of their contexts. They point to the impacts of:

- the IT revolution and the related changes in opportunities for changes to learning;

- changes to university funding arrangements including increased expectations of revenue generation;

- rapid growth and increased competition in the higher education market;

- increases in user pay expectations for those who attend university and the impact of paid work on attendance and engagement;

- changes in student expectations of university study;

- increased student diversity; and

- the increasing focus on accountability and standards.

Fullan and Scott (2009) and Scott et al. (2008) also point to the particular impacts of the widening participation movements and the related leadership challenges in managing the transition to university of students who are in the first generation of their family to attend university. The context in which university education now operates demands strong leadership and clever management.

This paper draws on two national research projects undertaken between 2010 and 2012 in Australia, each of which had a focus on leadership and management of teaching and learning in universities.

\section{Leadership lessons}

The first study was of leadership lessons from a particular national initiative designed to enhance teaching and learning in Australian universities. The Australian Learning and Teaching Council Limited (ALTC) established the Promoting Excellence Initiative (PEI) in 2007, inviting all eligible Australian institutions to apply for funding to build and consolidate their capacity to engage constructively with the programs of the ALTC. Forty-two of forty-four eligible Australian institutions took up this opportunity. The study, from which the current paper draws, sought to distil the key lessons about teaching and learning leadership and management that emerged from the Australian higher education sector's engagement with the PEI.

\section{The role of leaders}

The second national study from which the current paper draws was on effective teaching and support of students from LSES backgrounds in higher education. The second study focused in part on the role of university leaders and managers in facilitating and ensuring such teaching and support. The findings related to this aspect of the broader study have been combined with the findings from the first study and the combined findings are reported and discussed in this paper. 


\section{Meeting the particular needs of LSES students}

In the current policy context in Australia, it is critical that the Australian sector prepares itself to lead effective teaching and support of LSES students. Devlin (2010a) points out that students from LSES backgrounds may have particular challenges to overcome in order to succeed at university. She argues that there is a 'higher education student role' that needs to be learnt and mastered and that if a student has no familial or other experience of university study, as is the case for many LSES students, the successful student role will be unfamiliar and, therefore, difficult to understand, adjust to, learn, practise and master. Devlin (2010a) argues further that the tacit expectations of students and the language used within university discourses may also present particular challenges for LSES students. She suggests that having given LSES students access to university, the institution and the sector have a responsibility to articulate the successful student role; genuinely and proactively facilitate attempts by students to meet the expectations that institutions have of them; and contribute to facilitating student success. Institutional leadership plays a critical role in ensuring that all of this occurs.

\section{The need to use existing and new knowledge appropriately}

Reporting on the second study outlined above, Devlin, Kift, Nelson, Smith and McKay (2012a) argue that currently, the existing international and national expertise and experience in the area of enabling LSES student success is not being utilised as effectively as it might be in the Australian context. Acknowledging pockets of high experience and expertise in the country, Devlin et al. (2012a) suggest that the federal government policy targets mean new directions and new emphases for most Australian universities. As Devlin (2010b) notes, institutions and their staff are not yet ready to respond en masse to the changes the Australian sector has begun to experience. Effective leadership and management of teaching and learning within institutions at this time are crucial.

\section{Theoretical bases}

The theoretical bases of the current paper include contingency theories of leadership and management and inclusive and success-oriented theories of student experiences and learning. Each is explained in turn below.

\section{Contingency theories of leadership}

The first national research project on the leadership and management of teaching and learning in universities from which the current paper draws took the theoretical view that successful leadership of the enhancement of teaching and learning within universities is contingent on the context, environment and circumstances in which it occurs. The authors of the final report on this study argue that distributed leadership frameworks are the norm in most institutions and negotiating pathways through these frameworks requires leadership approaches that are innovative and relevant 
to the particular contexts in which leaders find themselves (Devlin, Smeal, Cummings \& Mazzolini, 2012b).

Drawing on the work of Middlehurst (1993), Marshall (2006) explains that the contingency theories of leadership recognise and acknowledge that different circumstances require different patterns of leader behaviour; that the nature of leadership will be shaped by a dynamic interaction between leader and context; and that leaders will have different constraints, demands and choices depending on their context. Thus, as Marshall (2006) notes, building leadership capacity from a contingency perspective '... is as much a process of developing the organisation as it is one of developing the professional knowledge and skills of those called to leadership positions' (p. 3). The application of the contingency theory of leadership demands a primary focus on organisational arrangements and characteristics rather than on attributes of individual leaders and managers per se.

The findings from the first project were distilled and are reported with this theoretical framework in mind. That is, broad lessons in teaching and learning leadership and management in terms of organisational factors were sought. The aim was to derive insights that could be shared with a wide range of leaders and managers at different levels within organisations to inform their leadership and management work. For the purposes of the current paper, the findings have been re-examined in the light of the Australian LSES agenda and context and findings particularly relevant to that agenda and context have been extracted. The full report on the study can be found in Devlin et. al, 2012b).

\section{Inclusive and success-oriented theories}

The second national project on LSES students on which the current paper draws adopted a theoretical approach drawn from constructivism (Bruner, 1996), transition pedagogy (Kift and Nelson, 2005; Kift, 2009) and inclusive practice (Waterfield and West, 2010). The project adopted Hockings (2010) view that rather than assuming that non-traditional students have 'special needs' that require attention outside the curriculum in adjunct programs, integrated curriculum design should instead be considered. The latter not only targets all students, it assumes that students bring to the learning environment varying resources in the cognitive, linguistic, knowledge and cultural domains.

The second study adopted a definition of inclusive teaching, adapted from extensive research and related work undertaken in the United Kingdom by Griffiths (2010). Griffith's definition was modified to fit the Australian context and to align with the study's focus on LSES students and on the various aspects of teaching, support, leadership and institutional culture. Inclusive teaching and support were conceptualised as "...incorporating the institutional policy framework and culture, the work of both academic and professional staff and the entire pedagogy, including curriculum design, delivery, evaluation, assessment, learning support and the learning environment" (Devlin et al. 2012a, p. X). 
As Devlin et al. (2012b) put it,

"Teaching for inclusion includes teaching technique and also: extends beyond technique, respecting students as individuals who have diverse backgrounds, different learning needs, and a variety of valuable prior experiences. By facilitating learning for inclusion, individual strengths and differences are acknowledged, fostered and maximised to enrich the student's own potential, knowledge, skills and understanding as well as that of others within the learning community. Such an approach is intentionally and thoroughly integrated into every part of an institution and implemented rigorously, vigorously and thoughtfully. (Adapted from Griffiths, 2010)" (p. 7)

The theoretical and philosophical underpinnings of the second study were deliberately 'success-focused' (Devlin, 2009). Noting that much understanding of the issues facing LSES students has come from research and investigation focused on the barriers to success and the problems LSES students face, this national study deliberately adopted an approach focused on the success of LSES students. This meant a focus on articulating success-oriented policy and practice that universities might adopt in relation to LSES students in higher education.

As Devlin (2009) argues in relation to another Australian equity student group, Indigenous students, "Giving prominence to a research-led focus on 'what works' in terms of ... student equity in higher education will provide evidence-based guidance for policy and practice" (pp. 1-2). She argues further that, "Through ... leveraging the experience of the many hundreds of successful ... university graduates, it may be possible to articulate some of the ways in which higher education success has been, and can be, achieved, despite the challenges that face ...[these] students (p. 2).

The second study took a similar view in relation to LSES students. The project recruited 'successful' LSES students. For the purposes of the project, 'successful' was defined as having completed at least one year of university study and reenrolled for another year. The aim in interviewing these students was to uncover aspects of these students' experiences that helped them stay at university, despite the challenges and obstacles they may have faced.

The findings from this study related to leadership and management that contributes to LSES student success were extracted and combined with findings from the first study and the overall results from both studies are reported in the current paper.

The first study on leadership was also success-focused. As the authors of the final report on this study note, in 2012 the Australian sector entered a demand-driven system and a context of reduced funding. Devlin et al. (2012a) argue that in such a context, "...it is critical to the quality of teaching and learning that 'what works' in higher education leadership of teaching and learning enhancement is highlighted and widely understood" (p. 13). Focusing on 'what works' necessitates determining what has been successful and focusing on those aspects of strategies. 
Scott et al. (2008) note that work over the past 20 years in Australia, Scandinavia, South Africa, New Zealand, Oman and Canada '... has repeatedly revealed that what our learning and teaching leaders want are practical, higher education specific and role-specific insights into what would be the best approach in taking 'good ideas' and making them work in ways that benefit both students and the university's "bottom line"' (p. vii). The success-oriented findings of both national studies are brought together in the current paper to provide a contribution to such insights.

As Devlin et al. (2012b) note, good practice, in teaching and learning per se and in the leadership of teaching and learning, should be shared to avoid 'reinventing the wheel', which is particularly valuable in the context of shrinking resources, increasing complexity and leadership succession challenges.

\section{Method}

The first national study of leadership of the enhancement of teaching and learning drew on three major data sources. These were:

1. A thematic analysis of final and evaluation reports on the Promoting Excellence Initiative from a representative sample of 18 Australian universities;

2. Interviews with 24 key teaching and learning leaders and staff from a representative sample of 10 Australian universities; and

3. An online survey of 88 teaching and learning leaders and practitioners at the four partner universities involved in the study.

For the purposes of the current paper, data from the 24 interviews were reexamined for data relevant to the focus on this paper. The analysis of the reports and the survey data provided contextual data that was helpful for interpreting the interview data but these data are not directly reported in the current paper.

Data for the second national study was collected from four major sources. These sources were:

1. A review of peer reviewed and other significant literature in the broad area of the experience of students from LSES backgrounds in higher education;

2. Interviews with 89 students who were from LSES backgrounds and in the first generation of their family to attend university and who had successfully completed at least one year of university study;

3. Interviews with 26 staff known for their expertise in teaching and/or supporting students from LSES backgrounds at university; and

4. An environmental scan of effective practice in programs, policy and other initiatives in teaching and/or supporting students from LSES backgrounds across Australia. 
For the purposes of the current paper, the data from interviews with 26 staff and 89 students were re-examined. The literature review provided context for interpreting the interview data but the findings from the review and the scan are not directly reported in this current paper. Findings from the first study can be found in Devlin et al. (2012a) and at the website www.lowses.edu.au.

Findings from the two studies as outlined above that related to the leadership and management of teaching and learning and support for LSES students were extracted and combined. This means that the conclusions of the current paper are informed by:

- A review of peer reviewed and other significant published literature and of reports on major initiatives within 18 Australian universities;

- Data on almost 30 effective programs and initiatives for LSES students across Australia; and

- A survey of 88 staff in four Australian universities.

The findings reported in this paper drew directly on:

- Interviews with 50 Australian university leaders and staff in more than a dozen Australian universities; and

- Interviews with 89 students from LSES backgrounds in three Australian universities.

The transcripts of the interviews were analysed as part of the original national studies using NVivo software. The outcomes of the analysis underwent rigorous inter-coder reliability and validity checks with a team of experienced researchers. Recoding and the creation and consolidation of codes were undertaken as necessary. For the purposes of this paper, the analyses of both sets of interviews were reexamined to determine the major themes that arose across the two studies. These themes are reported below.

\section{Results}

The analysis of the combined relevant findings from the two national studies revealed four key themes related to effective university leadership and management in a widening participation context in Australia. These themes are:

- Strategic focus and alignment;

- Reward and recognition.

- Resourcing; and

- Structure and organisation. 


\section{Strategic focus and alignment}

The analysis of the findings found that a strategic institutional focus on excellence in teaching and learning was critical to the effective university leadership and management in a widening participation context. Specifically, the findings indicate that efforts to lead and manage the improvement of teaching and learning need to be aligned with the strategic direction of the university. Where the institutions strategic priorities include excellence in teaching and learning and/or specifically supporting and facilitating the success of LSES students, leadership of effective teaching and learning in the current Australian context is more likely to be successful.

While it might seem self evident that efforts improve the quality of teaching and learning within an institution should be aligned with the strategic direction of the university, the findings indicate that tensions can often arise between overall institutional priorities and efforts to enhance the quality of teaching and learning (Devlin et al. 2012b). For example, there often tensions between discipline research endeavours and efforts to lead and manage the improvement of teaching and learning. Such tension, and in particular, the privileging of research over teaching and learning, can create a major cultural impediment to leading teaching and learning enhancement and enabling a focus on LSES student success.

The combined findings also point to the needs for both focused effort and an underpinning priority on supporting students. Each of these is discussed in more detail below.

\section{Focused effort}

The combined findings from the two studies examined from a success-oriented theory indicate that focused effort in a number of areas may be helpful to successful institutional leadership and management. For example, the data suggest that the reconciliation of competing foci on research on one hand, and on teaching and learning on the other, can be achieved to some extent. This can happen to some extent, for example, through the facilitation of an institutional commitment to research into and scholarship around teaching and learning. As well as the research into teaching and learning being beneficial as a research activity in itself with all the research outcomes that brings, additional benefits inherent in facilitating teaching and learning research and scholarship were also noted. These include: an increased reflection on teaching practice by teachers; a heightened awareness of the link between an individual's own teaching and their students' learning outcomes; more innovation in teaching; enhancing the quality of teaching and learning both within an institution and more broadly; and improved morale among teachers.

More particularly for LSES students, the enablement of the design of inclusive curriculum and assessment by university leaders was indicated as contributing to the success of LSES students. Such design would need to cater to diversity and integrate and scaffold opportunities for students to learn tertiary literacies alongside discipline content, while protecting academic standards. Leaders have a key role to play in 
setting a vision for such design, in marshalling the necessary resources to enable it to happen and in creating structures where academic staff can work collaboratively with support staff, library staff, academic skills, learning designers, eLearning specialists and other relevant staff to co-create inclusive curriculum.

\section{Underpinning priority on supporting students}

The combined findings of the study also show clearly the importance of an underpinning priority for university leaders on supporting students to enable their success. This priority needs to manifest in both strategic thinking and practical approaches to student learning and their wider experiences. The findings indicate that promoting and facilitating engagement and support between LSES students helps create a sense of belonging for them. This can be achieved through the provision of collaborative learning opportunities and peer-to-peer contact inside and outside the curriculum and of opportunities for families and communities to engage with the institution. Encouraging teaching staff to use early feedback and referral is also helpful as is the extension and enhancement of the provision and promotion of student services. Once again, leaders and managers have a critical role to play in ensuring all of this can occur within an institution.

In summary, the findings indicate that an alignment of the institution's strategy with the improvement of teaching and learning, coupled with a particular distribution of focus and effort and underpinned with a priority on supporting students are important elements of effective institutional leadership and management in a context of a growing proportion and number of LSES students.

\section{Reward and recognition}

The second theme to emerge from the combined findings was that of reward and recognition. The combined findings from the two national studies found that reward and recognition for university staff is a critical part of successful leadership and management for enhanced teaching and learning generally and for LSES student success particularly. The design and implementation of appropriate reward and recognition mechanisms and ensuring there are career pathways for those committed to teaching and learning are important components in the successful leadership of teaching and learning enhancement. University promotion criteria, in particular, must incorporate excellence in teaching and learning scholarship and practice in ways that can be readily understood by promotion panels so as to allow appropriate recognition and enable the sustainability of excellent teaching practice.

Staff workload was also found to be an important factor in successful leadership and management in universities in a widening participation context. The findings indicate that one major factor inhibiting efforts to improve teaching and learning in Australian universities is high staff workloads. The evidence indicates that staff have a lack of time to engage with, and contribute to, efforts to enhance teaching and learning. This finding mirrors those of several other recent Australian studies of the changing academic profession (see for example Coates et al. 2009). When teaching 
and learning involves growing numbers of LSES students, as it increasingly does in most Australian universities, the findings from the two studies indicate that the challenges of inclusive teaching and of providing detailed help, feedback, referral and support must be taken into account in determining workload models and appropriate levels of resourcing provided to ensure teachers and support staff can do their work with these students effectively. Unbundling the academic role and allocating administrative and other teaching-related tasks to staff who are qualified and able to complete them without detailed disciplinary knowledge that academic staff typically have is another approach worth considering.

Unfortunately, however, there are no simple answers to the challenges inherent in the workload theme reported here. As Devlin et al. (2012b) put it in one of the original national study reports, "If leaders in Australian universities wish to enhance teaching and learning, fresh thinking, policy and planning is needed around academic and professional staff roles and workload allocation" (p. 5).

\section{Resourcing}

A third theme to emerge from the analysis of the combined findings was resourcing. Somewhat unsurprisingly, it was found that embedding and sustaining good teaching and learning practice in the current Australian context requires high level support within an institution. Effective support was found to include both senior executive championing of teaching and learning enhancement and institutional investment in the form of funding and the resourcing of positions and initiatives, allocated as part of the university's planning and budget cycle.

More specifically for LSES students, effective support of these students to enable success includes actively minimising financial challenges for students. As well as promoting financial services and support available and facilitating access to government payment options, the findings indicate the importance of institutions minimising student costs through providing loans, hire services, free car parking and the like. There are clearly cost implications for institutions inherent in such support but the benefits in terms of student retention and an improved student experience are likely to provide a significant counterbalance.

\section{Structure and organisation}

The fourth theme to emerge from the analysis was related to structure and organisation of teaching and learning related leadership, guidance and support.

The findings of the research showed that a distributed institutional support structure for teaching and learning enhancement, coordinated from the centre, was perceived to be the most effective approach. Most commonly this involved cooperation between a central teaching and learning unit or centre and one or a combination of: teaching and learning committees; associate deans (teaching and learning) or equivalent in each Faculty; and educational development staff located in each Faculty; as well as other teaching and learning leaders at various levels throughout 
the organisation. The precise arrangements will depend on the context and history of structure and organisation, as well as on personnel in place in various roles.

\section{Conclusion}

Focusing on both teaching and learning leadership insights, and on the evidence about what helps students from LSES backgrounds to succeed, this paper reports on high level, evidence-based themes that have emerged from an analysis of the combined findings of two nation-wide studies in Australia.

Applying a contingency theory of leadership and a conceptual framework that deliberately focuses on student success, the themes that emerged from this study were: an institutional focus on teaching and learning and LSES student success; looking after teachers at the coalface who teach LSES students; ensuring adequate resourcing and creating infrastructure that fits the institutional context. A combination of institutional strategic alignment; mechanisms to recognise and reward excellence; symbolic and fiscal support; and coordinated support structures provide the basis of effective university leadership and management in the Australian context.

It is critical to understand and learn from 'what works' in the leadership and management of teaching and learning in a context of shrinking resources and one that incorporates a 'growing list of change forces in the environment that are challenging universities with ferocious intensity' (Fullan and Scott, 2009, p.1).

Recent changes to higher education policy in Australia mean that leadership is an area in which the sector must be proactive if it is to meet national targets. The results of the analysis presented in this paper can assist Australian universities to take the steps necessary to work towards these targets.

It could be argued that the key findings seem - at least with the benefit of some hindsight - somewhat obvious, but this does not invalidate them nor lessen their importance. It must be said, however, that the 'theory' of how to lead the enhancement of teaching and learning in higher education in a widening participation context drawn from the findings is relatively straightforward in comparison to the reality of acting on these findings. One might ask how feasible it is to make the sorts of changes that might be required to enact the themes reported here in a large and complex organization, often with multiple campuses in geographically dispersed locations and always with multiple stakeholders, agendas and purposes. While the type and scope of changes that might be required would be neither easy nor convenient, one could argue that they are critical to the success of the widening participation agenda and that change is only possible with the intent and commitment to make it. The findings provide the guidance necessary for decisions about where to direct energies and resources should an institution make the commitment to operationalising the changes necessary to better ensure LSES student success. 
It is hoped that the findings presented here will provide useful guidance to leaders and managers in the Australian higher education sector in their efforts with LSES students. This would help ensure that the significant effort being made by institutions to build aspirations and attract increasing numbers of LSES students to higher education is not wasted, and the lives of many LSES students are not adversely affected, through unnecessary and avoidable attrition from university.

Acknowledgements: The two national research projects on which this article is based were funded by the Office for Learning and Teaching (OLT) in the Australian Department of Innovation, Industry, Science, Research and Tertiary Education (DIISRTE) and led by Deakin University. The views expressed in this article are not necessarily those of the OLT, DIISRTE or Deakin University. I also gratefully acknowledge the work of my colleagues and collaborators in both national studies.

\section{References}

Australian Government (2009). Transforming Australia's Higher Education System. Canberra: Commonwealth of Australia.

Bradley, D., P. Noonan, H. Nugent and B. Scales. (2008). Review of Australian Higher Education Final Report. Canberra: Australian Government Printing Service.

Bruner, J. (1996). The Culture of Education. Cambridge, MA: Harvard University Press.

Coates, H., Dobson, I., Edwards, D., Friedman, T., Goedegebuure, L. \& Meek, V. L. (2009). The Attractiveness of the Australian Academic Profession: A Comparative Analysis, LH Martin Institute and ACER, Melbourne.

Devlin, M., Kift, S., Nelson, K., Smith, L. and McKay, J. (2012a). Effective teaching and support of students from low socioeconomic status backgrounds: Resources for Australian higher education. Final Report. Office for Learning and Teaching, Sydney: Commonwealth of Australia.

Devlin, M., Smeal, G., Cummings, R. and Mazzolini, M. (2012b). Leading sustainable improvement in university teaching and learning: Lessons from the sector. Office for Learning and Teaching, Sydney: Commonwealth of Australia.

Devlin, M. 2009. Indigenous higher education student equity: Focusing on what works. Australian Journal of Indigenous Education, 38, 1-8.

Devlin, M. (2010a). Non-traditional university student achievement: Theory, policy and practice in Australia. Keynote Address 13th Pacific Rim First Year in Higher Education Conference, 27-30 June 2010, Adelaide, Australia.

Devlin, M. (2010b). Improved access needs on- campus support. The Australian. September 29, 2010. Accessed 25 February, 2013 from: http://www.theaustralian.com.au/higher-education/opinion/improved-access- 
needs-on-campus-support/story-e6frgcko-1225931051379

Fullan, M. and Scott, G. (2009). Turnaround Leadership for Higher Education. San Francisco: Jossey-Bass.

Griffiths, S. (2010). Teaching for Inclusion in Higher Education: A guide to practice. York: Higher Education Academy, United Kingdom and All Ireland Society for Higher Education.

Hockings, C. (2010) Inclusive learning and Teaching: Research Synthesis. York: Higher Education Academy.

Kift, S. and K. Nelson. (2005). Beyond curriculum reform: Embedding the transition experience. In A. Brew and C. Asmar (Eds) Higher Education in a Changing World. Research and Development in Higher Education, 28, 25-235.

Kift, S. (2009). Final Report for ALTC Senior Fellowship Program. ALTC. Accessed 25 February, 2013 from: http://www.olt.gov.au/resources?text=sally+kift+fellowship

Marshall, S. J. (2006). Occasional Paper - Issues in the Development of Leadership for Learning and Teaching in Higher Education, Sydney Australia: Australian Learning and Teaching Council.

Middlehurst, R. (1993). Leading Academics. Bristol, UK: Open University Press.

Scott, G., Coates, H., \& Anderson, M. (2008). Learning Leaders in Times of Change, Sydney Australia: Australian Learning and Teaching Council.

Tinto, V. (2008). Access without support is not opportunity. Inside Higher Education. Accessed 25 February, 2013 from:

http://www.insidehighered.com/views/2008/06/09/tinto

Waterfield, J. and West, B. (2010). Inclusive assessment Diversity and Inclusion - the Assessment Challenge. Plymouth: The University of Plymouth. Accessed 25 February, 2013 from: http://www.ntu.ac.uk/cadq/quality/res_learn_teach/118024.pdf 